\title{
Revelación del diagnóstico de virus de la inmunodeficiencia humana a niños $y$ adolescentes afectados por él y a sus cuidadores
} Disclosure of human immunodeficiency virus diagnosis in
children and adolescents affected by it and their caregivers

\author{
Lic. Adriana Malanca ${ }^{a}$, Dra. Irene Foradori ${ }^{a}$, Dra. Erica Stankievich ${ }^{a}$, \\ Dr. Hugo Pandullo y Dr. Marcelo Losso ${ }^{a}$
}

\section{RESUMEN}

En la actualidad, sabemos que los niños y púberes necesitan conocer sobre su salud o la de sus padres. No obstante, las familias afectadas por el virus de la inmunodeficiencia humana suelen demorar la revelación del diagnóstico por miedo al estigma y la discriminación o simplemente porque se preguntan cuándo y cómo comunicarlo. Presentamos la experiencia de aplicar un programa destinado a "revelar" el diagnóstico de virus de la inmunodeficiencia humana a niños, adolescentes y sus cuidadores. Elobjetivo fue describir y comprender el impacto del anuncio para colaborar en acciones que mejoraran la atención integral de las familias que vivían con el virus de la inmunodeficiencia humana.

Palabras clave: adolescente, cuidadores, infecciones por VIH, revelación, estigma social.

\section{ABSTRACT}

Children and adolescents need to know about their health or that of their parents. However, families affected by human immunodeficiency virus often delay disclosure of diagnosis for fear of stigma or discrimination or simply because they wonder when and how to communicate it. We present the experience of implementing a program to "reveal" the human immunodeficiency virus diagnosis to children, adolescents and caregivers. The aim was to describe and understand the impact of disclosure and to collaborate on actions to improve comprehensive care for families living with human immunodeficiency virus.

Key words: adolescent, caregivers, HIV infections, disclosure, social stigma.

http:/ /dx.doi.org/10.5546/aap.2017.195

Financiado por el

Ministerio de Salud de

la Ciudad de Buenos

Aires a través de una

beca concursada y

otorgada a la Lic.

Adriana Malanca, convocatoria 2013, bajo dirección del Dr. Marcelo Losso.

Conflicto de intereses:

Ninguno que declarar.

Recibido: 27-6-2016

Aceptado: 24-11-2016 E, et al. Revelación del diagnóstico de virus de la inmunodeficiencia humana a niños y adolescentes afectados por él y a sus cuidadores. Arch Argent Pediatr 2017;115(2):195-199.

\section{INTRODUCCIÓN}

En la actualidad, y en relación con el impacto de las terapias antirretrovirales, se considera el virus de la inmunodeficiencia humana (VIH) / sida como una enfermedad crónica. No obstante, la revelación del diagnóstico a niños y adolescentes sigue siendo una dificultad. ${ }^{1}$ La falta de conciencia sobre el VIH puede generar fallas en la adherencia al tratamiento y en la adopción de medidas de prevención secundaria, y la población pediátrica es, en este sentido, un grupo de riesgo. Se recomienda tener acceso a información clara, fidedigna y sencilla, monitorear el proceso de revelamiento y ofrecer la posibilidad de un espacio de contención y soporte psicológico. ${ }^{2}$ Los cuidadores pueden presentar resistencias a informar por temor a generar angustia y estigma en los niños, y el proceso se ve demorado.

En este estudio de corte cualitativo, se realizó la acción de revelar y se describió el impacto del anuncio para comprender las dificultades actuales y colaborar en acciones que mejoraran la atención integral de las familias que vivían con VIH.

\section{POBLACIÓN Y MÉTODOS}

Nuestra experiencia se desarrolló

Cómo citar: Malanca A, Foradori I, Stankievich en el Hospital Ramos Mejía de la Ciudad Autónoma de Buenos Aires (CABA), en el período 2013-2015. Se solicitó la firma del consentimiento informado (CI) a todos los pacientes/ representantes legales de estos para participar en el estudio. Se solicitó la firma de un cuidador mayor de edad 
que acreditara estar a cargo del paciente. Se tomó un asentimiento en los pacientes mayores de 7 años (según normas vigentes en 2013).

La metodología fue eminentemente de corte cualitativo, mediante técnicas, tales como entrevistas individuales, la técnica gráfica de la casa/árbol/persona (house/tree/person; HTP, por sus siglas en inglés), ${ }^{3}$ como canal comunicativo y de conexión con el mundo interior infantojuvenil, y la encuesta APGAR-Percepción de la función familiar ${ }^{4}$ para conocer si la familia podía considerarse un recurso para los individuos o, por el contrario, influiría empeorando la situación.

La selección de la muestra fue no probabilística por conveniencia. Se les ofreció el estudio a los niños de entre 6 y 14 años y sus cuidadores afectados por el VIH/sida en seguimiento en el Servicio de Pediatría e Inmunocomprometidos, que no conocieran el diagnóstico, aceptaran participar y firmaran el consentimiento, a medida que iban concurriendo a sus controles clínicos en forma consecutiva.

Se realizaron, antes y después del revelamiento, entrevistas semidirigidas a los cuidadores. Las preguntas se combinaron entre abiertas, cerradas y de opción múltiple. Se administraron antes y después de la revelación para describir los siguientes dominios:

- Percepción subjetiva de la enfermedad en los cuidadores.

- Relaciones vinculares entre los padres y los niños/adolescentes.

- Accesibilidad a los Servicios de Salud Mental. Se administró el cuestionario APGARPercepción de la función familiar, que abordaba 5 funciones: adaptabilidad (capacidad de utilizar recursos intra- y extrafamiliares para resolver problemas en situaciones de estrés), participación (implicación en la toma de decisiones), crecimiento (maduración emocional y realización que alcanzan los componentes de la familia), afecto (relación de cariño que existe en la familia), resolución (tiempo para atender las necesidades de los otros miembros). El puntaje para cada dimensión osciló entre 0 y 4 puntos, que iba de "nunca" a "siempre". Según el puntaje obtenido, se interpretó función familiar normal: 7-10 puntos; disfunción moderada: 4-6 puntos; disfunción grave: 0-3 puntos.

Se utilizaron los principios de la teoría fundamentada para que las personas entrevistadas pudieran expresar sus percepciones y opiniones.

Con los niños/adolescentes, se realizaron, antes y después de la intervención, entrevistas semiestructuradas para establecer el nivel de información sobre la enfermedad, aspectos de la personalidad más inconscientes y madurez cognitiva. Se aplicó el test gráfico proyectivo HTP de Buck-Hammer para medir el estado emocional de los niños/adolescentes y el cuestionario APGAR-Percepción de la función familiar.

La acción de revelar incluyó los siguientes temas con material gráfico y soporte digital adaptados a edad y madurez cognitiva: sistema inmunológico: ¿qué pasa cuando nos enfermamos? Defendernos de quién y cómo; percepción de la enfermedad: ¿qué creo que tengo/tiene mi madre o padre?; sexualidad: quién soy, cómo me veo, cómo me ven, con quién me relaciono, cómo lo hago; enfermedad y tratamiento, consecuencias de la no adherencia.

\section{PLAN DE ANÁLISIS DE LOS RESULTADOS}

Se realizó una triangulación de datos. Se relacionaron los resultados obtenidos de las distintas técnicas. Se analizaron las entrevistas en forma inductiva según la teoría fundamentada. ${ }^{5}$ Los resultados recogidos de manera cuantitativa se analizaron de manera estadística no paramétrica. El nivel de significancia se consideró menor de 0,05 . Los cálculos se realizaron con el software SPSS libre.

\section{RESULTADOS}

Participaron 35 niños y 35 cuidadores. La muestra fue de 17 niños con VIH (el total de pacientes que cumplían con los criterios de inclusión era de 20; hubo 3 rechazos a participar) y 18 niños expuestos (cumplían con el criterio de inclusión 39 pacientes; hubo $46 \%$ de rechazo a participar). En el caso de los niños expuestos, el rechazo fue más alto de lo esperado; los cuidadores refirieron que preferían demorar o, incluso, ocultar su condición serológica.

\section{Características psicosociales del niño, adolescente y su entorno}

La media de edad fue de 10 años para los infectados perinatales y de 10,7 para los expuestos. La escolaridad fue acorde a la edad en 16/17 niños con VIH y 16/18 expuestos. Los indicadores psicosociales fueron levemente mejores para el grupo de niños expuestos (Tabla 1).

\section{Barreras de acceso a Servicios de Salud Mental}

En 24/35 casos, los cuidadores contaron con el recurso de Salud Mental al momento de la 
notificación del diagnóstico, pero muy pocos realizaron tratamientos psicológicos por lejanía con el centro de salud, falta de información sobre el aporte que podría brindar, conductas de negación, depresión y ansiedad.

\section{Estado emocional del cuidador antes y después de la intervención}

Cuidadores de niños con infección por virus de la inmunodeficiencia humana

En la evaluación basal de los cuidadores, 14/17 refirieron que enterarse de su condición serológica fue causa de sufrimiento psíquico (afectos de la esfera depresiva por su naturaleza distímica), sentimientos de soledad asociados con desamparo y tristeza. Algunos cuidadores refirieron conductas de negación con dificultades en su adherencia al tratamiento al inicio de este; 14/17 manifestaron sentimientos de baja autoestima y culpa. Consideraron que los principales problemas de convivir con la enfermedad eran el tratamiento y el miedo a la discriminación; 10/17 habían perdido a parejas o amigos por esta enfermedad, hacía más de 10 años que habían sido diagnosticados y presentaban más de un infectado en la familia. La necesidad de apoyo fue mayor para aquellos tutores de más edad o para los adolescentes y adultos jóvenes, cuya búsqueda de independencia entró en conflicto con la responsabilidad de cuidar padres enfermos y/o hermanos. Luego de revelar, una proporción de los cuidadores requirieron apoyo adicional: 12/17. Se reforzó la adherencia y la comprensión subjetiva de la enfermedad con entrevistas motivacionales.

\section{Cuidadores con virus de la inmunodeficiencia humana de niños sanos expuestos}

De los cuidadores, $4 / 18$ refirieron depresión; $5 / 18$, ansiedad; y $5 / 18$, consumo problemático de sustancias; $17 / 18$ recibieron diagnóstico $y$ tratamiento en el embarazo para evitar la transmisión perinatal. Relataron el impacto al conocer el diagnóstico, con sufrimiento psíquico; 14/18 manifestaron sentimientos de baja autoestima y culpa. Consideraron que los principales problemas de convivir con la enfermedad eran el tratamiento y el miedo a la discriminación.

Luego de revelar, requirieron apoyo adicional

TABla 1. Características psicosociales de los niños y sus cuidadores

\begin{tabular}{|l|c|c|}
\hline Datos sociodemográficos de niños y cuidadores afectados por el VIH (N: 35 díadas) \\
\hline Datos de los niños & & \\
\hline Edad media en años & 10 & 10,7 \\
\hline Escolaridad acorde a la edad & 16 & 16 \\
\hline Residen en CABA & 10 & 15 \\
\hline & & \\
\hline Datos de los cuidadores & & 18 \\
\hline Madres con infección por VIH & 17 & 18 \\
\hline Madres convivientes & 7 & 15 \\
\hline Madres fallecidas & 10 & 3 \\
\hline Padres con infección por VIH & 16 & 11 \\
\hline Padres fallecidos & 5 & 4 \\
\hline Padres convivientes & 12 & 7 \\
\hline Cuidador principal con trabajo estable & 8 & 11 \\
\hline Cuidador principal con trabajo temporario & 6 & 5 \\
\hline Cuidador principal sin trabajo & 3 & 2 \\
\hline Estudios primarios & 9 & 11 \\
\hline Estudios secundarios & 6 & 6 \\
\hline Estudios terciarios/universitarios & 2 & 1 \\
\hline Reciben subsidio a causa de la infección por VIH & 10 & 14 \\
\hline
\end{tabular}

VIH: virus de la inmunodeficiencia humana; CABA: Ciudad Autónoma de Buenos Aires. 
6/18. La intervención de revelar permitió que los niños comenzaran a apuntalar a los padres para que cumplieran con sus tratamientos y se encontraran con buena salud; 12/18 refirieron que decir la verdad les había resultado liberador.

\section{Estado emocional de los niños y adolescentes antes y después de la intervención de "develar". Niños con virus de la inmunodeficiencia humana}

Se utilizó la técnica gráfica HTP. La presencia de determinados elementos pudo deberse a circunstancias temporales y no a rasgos permanentes de su temperamento o personalidad ni ser el resultado directo de la intervención de revelar. Los indicadores gráficos más presentes fueron evitación social, aislamiento e inseguridad, que remitieron moderadamente (registro psicodinámico).

Se observaron diferencias por rangos de edad y por contextos socioafectivos (registro fenomenológico).

Entre 8 y 9 años, tenían más dificultades en la comprensión. Las formulaciones pediátricas siguieron siendo una dificultad. Contaban con contención afectiva familiar.

El comportamiento mejoró, así como la adherencia al tratamiento. La información se reforzó desde el hogar y el equipo de salud.

En el rango de 10-11 años, si bien no se observaron manifestaciones que expresaran malestar, se abrieron preguntas sobre la continuidad del tratamiento y las modalidades de transmisión del virus. Preguntaron acerca de sus hermanos sanos. Protestaron por el tratamiento, pero presentaron buena adherencia. Hubo contención afectiva familiar; 6/18 vivían en el conurbano bonaerense y tenían más de una hora de viaje hacia el hospital, lo que dificultaba el seguimiento. Se reforzaron contenidos con el uso de tecnología digital, mail y Whatsapp. Contaron con apoyo afectivo familiar.

El rango 12-14 presentó más dificultades en el impacto inmediato (2 mamás presentaban depresión con conductas y mensajes muy negativos). Adicionalmente, tenían un componente de dificultad social grave y conflictividad familiar. No se logró optimizar la adherencia en un paciente con serias dificultades sociales, en el que el padecimiento atravesaba muchos órdenes distintos que no solo tenían que ver con la falta de información.

\section{Niños expuestos}

Los indicadores gráficos predominantes fueron evitación social, impulsividad, aislamiento y compensación narcisista; 8/18 tenían cuidador principal y un hermano infectado, no mostraron sorpresa, preguntaron sobre el pronóstico, comprendían que los hermanos tenían enfermedad adquirida de los padres. Manifestaron preocupación por la adherencia e intentaron colaborar con sus padres. Solo 3/18 refirieron haber recibido información sobre el VIH en ámbitos escolares.

En el rango de 12 a 14 años, hubo falta de percepción del riesgo. Podían gestionar el secreto del VIH como un mandato impuesto desde las expectativas de la familia, ya que no consideraban la necesidad de ocultar la enfermedad.

La tercera parte $(6 / 18)$ vivía en el conurbano bonaerense y tenía más de una hora de viaje hacia el hospital, lo que dificultaba el seguimiento; $2 / 18$ presentaron graves problemas socioeconómicos.

Impacto sobre las relaciones vinculares de los niños/adolescentes y sus cuidadores.

APGAR familiar en pacientes con virus de la inmunodeficiencia humana.

En relación con si la familia podía considerarse un recurso para los individuos, $3 / 17$ presentaron disfuncionalidad moderada antes de la revelación.

Los resultados luego de la intervención en los valores totales fueron significativos para los cuidadores y no para los niños. No obstante, los niños presentaron mejoría significativa en los dominios adaptabilidad y crecimiento. Los cuidadores mejoraron en adaptabilidad, participación y resolución. Además de percibir el apoyo familiar, se implicaron en la toma de decisiones y se ocuparon más de otros miembros de la familia.

\section{APGAR en niños expuestos}

Tres de los 18 niños presentaron disfuncionalidad moderada antes de la intervención.

Los resultados luego de la intervención fueron significativos para los niños, con valores más altos en los dominios participación, crecimiento y resolución, lo cual se podía interpretar como mayor involucramiento en las responsabilidades familiares, madurez y dedicación hacia los otros miembros. 
Los resultados fueron significativos en los cuidadores. Se destacó la dimensión adaptabilidad, lo que implicó pensar a la familia como un recurso favorable.

\section{Comentarios}

Es importante brindar información apropiada sobre el VIH/sida a los niños desde los primeros momentos, relacionarla con su propia experiencia y quitarle, al momento de revelar, la carga negativa que conlleva.

Si bien los adolescentes con infección requirieron apoyo adicional, sobre todo, en relación con la adherencia al tratamiento, esta se vio afectada por múltiples factores. Las problemáticas sociales graves fueron motivos de sufrimiento psíquico y depresión, y afectaron la continuidad de los tratamientos.

Comprender el diagnóstico les permite responsabilizarse progresivamente en su pronóstico y calidad de vida. Los niños expuestos refirieron, a partir de conocer el diagnóstico, participar de manera activa y colaborar con el tratamiento al recordarles a sus padres las tomas de medicación, lo que generó un ambiente sin prejuicios y discriminación.

Los rangos de edad pueden influenciar en el distinto nivel de impacto. Algunos adolescentes que tuvieron muy demorado el acceso a la información y convivían con problemáticas sociales graves presentaron, en lo inmediato, un impacto negativo y requirieron apoyo.

El hecho de que, durante la adolescencia, se encuentren en desarrollo tanto las estructuras de apoyo ${ }^{6}$ como la autoestima ${ }^{7}$ podría también explicar los resultados discordantes en cuanto al impacto inmediato y negativo de la intervención.

El enfoque cualitativo no permite inferir que los datos sobre estados emocionales sean un resultado directo de la intervención. No obstante, un eficiente proceso de revelamiento facilita la aceptación de la enfermedad, lo que permite una mayor comunicación familiar, estimula la adherencia a los tratamientos y, fundamentalmente, promueve una mejor calidad de vida para los niños y los adultos.

\section{REFERENCIAS}

1. Adaszko A. Trayectorias de vida y manejo dela enfermedad en la vida cotidiana de adolescentes que crecieron viviendo con VIH/sida. Actualizaciones en Sida 2012;(20)75:19-32.

2. Pavía-Ruz N, Tovar Larrea P, Muñoz Hernández R. Trastornos psicológicos en niños y adolescentes infectados perinatalmente por el VIH. Enf Infec y Microbiol 2003;23(4):126-32.

3. Buck JN. Manual y guía de Interpretación de la técnica de dibujo proyectivo HTP Casa, árbol, persona. México DF: Manual Moderno; 1992.

4. Smilkstein G. The family APGAR: a proposal for a family function test and its use by physicians. J Fam Pract 1978;6(6):1231-9.

5. Glasser B, Strauss A. El método de comparación constante de análisis cualitativo. En The discovery of grounded theory: Strategies for qualitative research. New York: Aldine Publishing Company; 1967.Págs.101-15.

6. Barra E, Cerna R, Kramm D, Veliz V. Problemas de salud, estrés, afrontamiento, depresión y apoyo social en adolescentes. Ter Psicol 2006; 4(1):55-61.

7. Klimstra TA, Hale WW, Raaijmakers QAW, Branje SJ, et al. Maturation of personality in adolescence. J Pers Soc Psychol 2009;96(4):898-912. 